\title{
Patterning Surfaces through Photografting of Iodonium Salts
}

\author{
Jérôme Médard, ${ }^{\mathrm{a}}$ Catherine Combellas, ${ }^{\mathrm{a}}$ Frédéric Kanoufi, ${ }^{\mathrm{a}}$ Jean Pinson,,${ }^{\mathrm{a}}$ \\ Jérôme Chauvin, ${ }^{\mathrm{b}}$ Alain Deronzier ${ }^{\mathrm{b} *}$ \\ a Sorbonne Paris Cité, Université Paris Diderot, ITODYS, UMR 7086 CNRS, 15 rue J-A de Baï, 75013 Paris, \\ France.

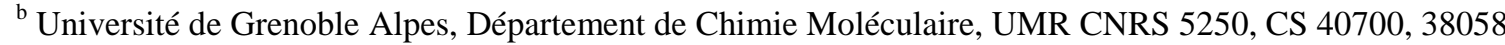 \\ Grenoble cedex 9, France.
}

\begin{abstract}
A gold surface immersed in an aprotic iodonium salt solution containing a photosensitizer is patterned by irradiation with a blue light through a mask. The photochemical behavior of three photosensitizers in the presence of (4-nitrophenyl)(2,4,6-trimethylphenyl)iodonium triflate $\mathbf{I}$ is fully characterized [luminescence quantum yield $\Phi_{\mathrm{L}}$ and lifetime $\tau_{\mathrm{L}}$, quenching rate constant $\left(\mathrm{k}_{\mathrm{q}}\right), \Delta \mathrm{G}^{\circ}$ and quantum yield $\left.\left(\Phi_{R}\right)\right]$. The key species for the surface modification are aryl radicals formed under irradiation through reduction of the iodonium salt by the excited state of the photosensitizer. The pattern consists of a polyaryl film obtained from aryl radicals that react with the surface and also with the first grafted aryl groups. The modified surface is characterized by IR, XPS, AFM and electrochemistry. The submillimetric pattern is observed by condensation and Scanning Electrochemical Microscopy. This method permits to obtain strongly bonded patterns with variable substituents on the aryl ring; it allows preparing various patterns of multifunctional surfaces that can be used for sensors and diagnostics, or to limit hydrophilic paths within hydrophobic films for surface tension confined microfluidic devices.
\end{abstract}

\section{INTRODUCTION}

Surfaces can be modified by attachment of organic groups (carbon, metals, semiconductors, polymers...). Different organic groups can be used to attach derivative films to surfaces (thiols on gold, ${ }^{1}$ alkenes on $\mathrm{Si}^{2}{ }^{2}$ silanes ${ }^{3}$ and phosphonic acids ${ }^{4}$ on oxides). Diazonium and iodonium cations ( $\mathrm{Ar}-\mathrm{N} \equiv \mathrm{N}^{+}, \mathrm{Ar}-\mathrm{I}^{+}-\mathrm{Ar}$ '), via their reduction, are also excellent candidates to perform the modification of many materials (conductive or not). ${ }^{5-8}$ Moreover, patterning a surface with such chemical groups permits to prepare specifically located chemical functions (chemical patterning). ${ }^{9-11}$ 
In a general way, different physical and chemical methods are available for patterning surfaces with organic groups, for instance: microcontact printing, scanning probe lithography, electrografting, photografting etc. Microcontact printing involves stamps that are inked and then pressed on the surface. ${ }^{12}$ For example, polydimethylsiloxane (PDMS) stamps are inked by dipping in a solution of a thiol terminated molecule and pressed against an $\mathrm{Au}$ surface; after seconds a dense Self-Assembled Monolayer (SAM) is formed on the substrate providing micrometric patterns after removal of the stamp. ${ }^{12}$ Inkjet printing ${ }^{13}$ uses droplets of organic ink that are propelled onto paper, plastic, or other substrates as in the printers used in offices; it permits, for example, printing on polymers for flexible electronics or on paper for microfluidic paper-based analytical devices. ${ }^{14}$ Scanning probe lithography makes use of a very thin tip to modify the surface: i) in Scanning ElectroChemical Microscopy (SECM) a micrometer (and below) electrode is positioned close to a surface to modify or probe this surface, ${ }^{15}$ for example, microscopic, enzymatically active spots on SAMs of alkanethiolates on gold were obtained by a combination of localized desorption induced by SECM followed by chemical derivatization. ${ }^{16}$ ii) Dip-pen nanolithography uses an AFM tip for the local delivery of a chemical reagent to a surface ${ }^{17}$; for example ferroelectric $\mathrm{PbTiO}_{3}$ nanodots down to $37 \mathrm{~nm}$ were deposited on $\mathrm{Nb}$-doped $\mathrm{SrTiO}_{3}$ to prepare ferroelectric random access memories. $^{18}$

The reduction of aryl diazonium salts has been used for patterning surfaces using different methods. ${ }^{11}$ Some examples may be mentioned: the grafted layer obtained from a first diazonium salt was locally removed by an AFM tip (nanoshaving) ${ }^{19}$ and the exposed unmodified surface grafted with a second diazonium salt; ${ }^{20}$ nanospotting was achieved with an aryl diazonium cation transferred from an organic phase (diazonium ink) inside a nanopipette to an external aqueous phase and reduced on a cathodic highly ordered pyrolytic graphite (HOPG) surface to give $500 \mathrm{~nm}$ spots of aryl modified HOPG surfaces; ${ }^{21}$ graphene oxide was locally reduced under a micrometric electrode by SECM to produce lines of reduced graphene oxide $(\sim 50 \mu \mathrm{m}$ wide $) .^{22}$ Microcontact printing has been achieved by pressing a carbon surface with a PDMS stamp, filling the microchannels with a diazonium salt solution, biasing the carbon surface to reduce the salt and perform the electrografting in the channels, providing lines of aryl modified carbon. ${ }^{23}$

Patterning surfaces by photolithography, which is widely used in the microelectronic industry for the fabrication of integrated circuits, ${ }^{24}$ offers the advantage of modifying the surface in a local and precise way thanks to the use of masks. Indeed, light is shined through a mask to transfer the pattern to the surface owing to a photoreaction in the irradiated regions; for 
example a resin (photoresist) deposited on a silicon wafer becomes soluble upon irradiation and the silicon dioxide insulating substrate can be etched in the unprotected regions. With deep UV light patterns below $20 \mathrm{~nm}$ are obtained. ${ }^{25}$

Photosensitized grafting of diazonium salts has been demonstrated, ${ }^{26-28}$ including local photografting. Millipipettes permit to pattern PVC surfaces with grafted nitrophenyl spots ${ }^{26}$ while nanosphere lithography on gold (the mask consists of a layer of $500 \mathrm{~nm}$ silica spheres deposited on the surface) provides an array of triangular spots corresponding to the unmasked surface between the spheres. ${ }^{27,29}$ However, photografting through a mask is not possible with diazonium salts, which react spontaneously with nearly any surface, including gold, and results in a thick layer in the irradiated regions and a thinner film in the shaded regions.

Iodonium salts are also capable of producing aryl radicals by reduction. They can be electrografted on surfaces providing aryl films as thin as monolayers. ${ }^{8,30-41}$ The key intermediate is the aryl radical as with diazonium salts, but, in contrast to diazonium salts, iodonium salts are less reactive and the spontaneous reaction on surfaces is more difficult as a consequence of their more negative reduction potentials. ${ }^{31}$ This lower reactivity has permitted the direct patterning of gold surfaces by SECM. ${ }^{32}$ For these reasons, iodonium salts are good candidates for photo-patterning.

In addition the photo-induced reduction of iodonium salts with dyes has been demonstrated since the end of seventies ${ }^{42}$. Rate constants of the quenching of the excited state of the $\mathrm{Ru}(\mathrm{bpy})_{3}{ }^{2+}$ (bpy: 2,2'-bipyridine) photosensitizer by some substituted diphenyliodonium salts are moderate: between 1.1 and $4.1 \times 10^{8} \mathrm{M}^{-1} \mathrm{~s}^{-1}{ }^{43}$ Such sensitized photochemical cleavage of iodonium salts has been used to initiate the polymerization of vinylic compounds. ${ }^{44,45}$ Interestingly, in the presence of a photoinitiator with a naphthalimide-phthalimide structure, under soft blue light irradiation of diphenyliodonium the EPR spectrum of the phenyl radical was evidenced, demonstrating that the inhibition takes place by an electron transfer mechanism. ${ }^{45}$ Finally this photo generation of aryl radicals based on iodonium salts was used in some recent examples of photoredox catalytic arylation and $\mathrm{C}-\mathrm{C}$ coupling reactions. ${ }^{46}$

The present paper describes the successful photografting and patterning of a gold surface by nitrophenyl groups through the irradiation of (4-nitrophenyl)(2,4,6-trimethylphenyl)iodonium triflate $\mathbf{I}$ chosen as an example in the presence of three redox photosensitizers $\left[\operatorname{Ru}(b p y)_{3}\right]^{2+}$, $\left[\mathrm{Cu}(\mathrm{dpp})_{2}\right]^{+} \quad(\mathrm{dpp}=2,9$-diphenyl-1,10-phenanthroline $)$ and $\left[\mathrm{Cu}(\mathrm{dap})_{2}\right]^{+} \quad\left(\operatorname{dap}=2,9^{\prime}\right.$-bis $(p$ anisyl)-1,10-phenanthroline (Scheme 1). 
<smiles>CC[C+](C)CC(C)C</smiles>

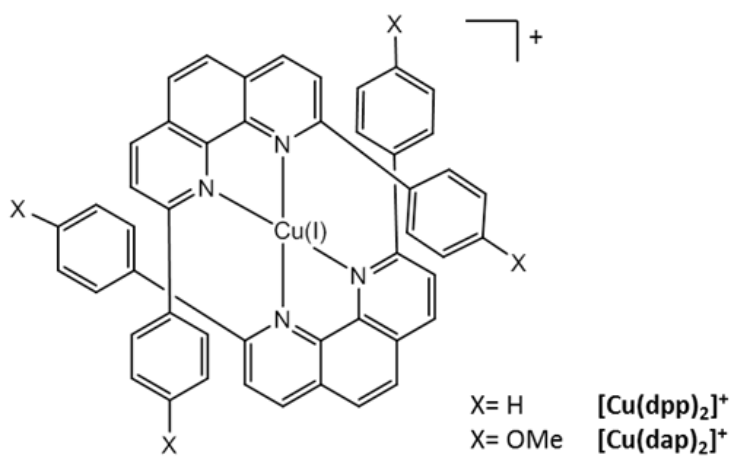

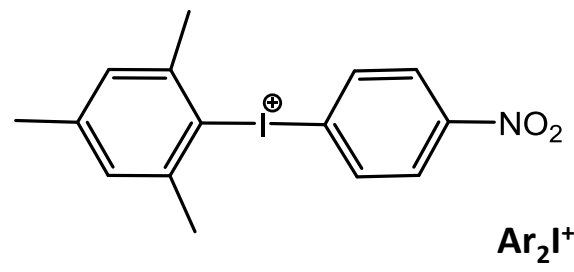

Scheme 1. Schematic representation of the three photosensitizers $\left[\mathrm{Ru}(\mathrm{bpy})_{3}\right]^{2+}, 2 \mathrm{PF}_{6}^{-} ;\left[\mathrm{Cu}(\mathrm{dpp})_{2}\right]^{+}, \mathrm{BF}_{4}^{-}$; $\left[\mathrm{Cu}(\text { dap })_{2}\right]^{+}, \mathrm{Cl}^{-}$and the iodonium salt $\mathrm{Ar}_{2} \mathrm{I}^{+}, \mathrm{CF}_{3} \mathrm{SO}_{3}^{-}(\mathbf{I})$.

\section{EXPERIMENTAL SECTION}

Chemicals. The iodonium salt used is (4-nitrophenyl) (2,4,6-trimethylphenyl)iodonium triflate (I) from Sigma-Aldrich $\left(\mathrm{C}_{16} \mathrm{H}_{15} \mathrm{~F}_{3} \mathrm{INO}_{5} \mathrm{~S}, 98 \%\right)$. The two photosensitizers, $\left[\mathrm{Ru}(\mathrm{bpy})_{3}\right]\left(\mathrm{PF}_{6}\right)_{2}(97 \%)$ and $\left[\mathrm{Cu}(\mathrm{dap})_{2}\right](\mathrm{Cl})$, were purchased from Sigma-Aldrich and used as received. $\left[\mathrm{Cu}(\mathrm{dpp})_{2}\right]\left(\mathrm{BF}_{4}\right)$ was synthesized according to litterature. ${ }^{47} \mathrm{~N}, \mathrm{~N}$ diisopropylethylamine (DIPEA) was obtained from Sigma-Aldrich $\left(\mathrm{C}_{8} \mathrm{H}_{19} \mathrm{~N}, 99 \%\right.$,).

Substrates. Gold coated silicon wafers from Sigma-Aldrich (100 nm gold) were cut into $1 \times 1$ $\mathrm{cm}^{2}$ pieces. They were successively rinsed in a bath of sulfuric acid (95\%) for $2 \mathrm{~s}$, and with distilled water and under sonication in distilled water, acetone and absolute ethanol (380 s each) and finally dried by an argon stream.

Grafting of Gold Plate by Iodonium Salt. A piece of a gold coated silicon wafer was placed in a test tube that was hermetically closed by a septum and purged by a stream of argon. 100 
$\mu \mathrm{L}$ of a mixture of $\mathbf{I}(0.1 \mathrm{M})$, photosensitizer $(12.5 \mathrm{mM})$ and DIPEA $(0.2 \mathrm{M})$ in ACN were deposited with a needle on the Au surface, without opening the reactor as the reaction is very sensitive to oxygen. Irradiation was produced by a blue LED strip arranged around the tube. During irradiation, the test tube was cooled at $\sim 0{ }^{\circ} \mathrm{C}$ to limit the possible spontaneous reactions on gold. After $10 \mathrm{~min}$, irradiation was stopped, the solution was evaporated and the sample was rinsed with ethanol, sonicated for $380 \mathrm{~s}$ in absolute ethanol to remove any adsorbed material and finally dried under an argon stream before characterization by different methods. Images of the experimental setup are given in Figure S1 (Supporting Information).

Photophysics. Absorption and emission spectra were recorded with a Varian Cary 300 spectrophotometer and a fluoromax 4 Horiba spectrofluorometer, respectively. The luminescence lifetime of the complexes was measured after irradiation at $\lambda=405 \mathrm{~nm}$ (obtained with a pulsed diode laser (LDH-PC-405) using Fluotime 200 from PicoQuant for the decay acquisition). All samples were prepared inside a glovebox in a $1 \mathrm{~cm}$ quartz cell containing deoxygenated ACN. The samples were maintained under anaerobic conditions with a teflon cap. Emission quantum yields, $\phi_{\mathrm{L}}$, were determined at $25^{\circ} \mathrm{C}$ with an $\mathrm{ACN}$ solution of $\left[\mathrm{Ru}^{\mathrm{II}}(\mathrm{bpy})_{3}\right]\left(\mathrm{PF}_{6}\right)_{2}\left(\phi_{\mathrm{L}}{ }^{\text {ref }}=0.062\right)$ as a standard and using an optically diluted methodology. ${ }^{48}$ Photoreduction of $\mathbf{I}$ was performed under continuous irradiation using a Xe lamp (150 W, Hamamatsu L8253) and a UV-Hot filter (between 400-700 nm; 03MHG101). The intensity reaching the sample was estimated by actinometry using the ferrioxalate salt $\left(\mathrm{K}_{3}\left[\mathrm{Fe}\left(\mathrm{C}_{2} \mathrm{O}_{4}\right)_{3}\right]\right.$ with $\left.\phi_{\mathrm{R}}{ }^{\text {ref }}=1\right) .{ }^{49}$ The uncertainties are estimated as $\pm 2 \mathrm{~nm}$ for $\lambda_{\max }, 10 \%$ for $\varepsilon$, $20 \%$ for $\phi$ and $5 \%$ for $\tau$.

IRRAS. Spectra of modified plates were recorded using a purged (low $\mathrm{CO}_{2}$, dry air) Jasco FT/IR-6100 Fourier Transform Infra Red Spectrometer equipped with MCT (mercurycadmium-telluride) detector. For each spectrum, 1000 scans were accumulated with a spectral resolution of $4 \mathrm{~cm}^{-1}$. The background recorded before each spectrum was that of a cleaned substrate. RAS spectra were recorded with a RAS accessory (Jasco RAS PR0410-H).

XPS. X-ray photoelectron spectra were recorded using a Thermo VG Scientific ESCALAB 250 system fitted with a micro-focused, monochromatic Al K $\alpha$ X-ray source (1486.6 eV) and a magnetic lens, which increases the electron acceptance angle and hence the sensitivity. The pass energy was set at $150 \mathrm{eV}$ and $40 \mathrm{eV}$ for the survey and the narrow regions, respectively. The Avantage Software, version 4.67, was used for digital acquisition and data processing. The spectra were calibrated against C1s set at $285 \mathrm{eV}$. 
$\boldsymbol{A F M}$. AFM images were recorded with a NT-MDT Solver pro equipment. AFM topography was performed in the intermittent contact mode with standard silicon cantilevers. Image analysis was achieved with the free software WSxM.

Ellipsometry. Thicknesses of the films on gold plates were measured with a mono wavelength ellipsometer Sentech SE400 with a SE400 advanced 2.20 version software. The following values were taken for gold: $\mathrm{ns}=0.21, \mathrm{ks}=3.41$. They were measured on cleaned surfaces before grafting. The film thicknesses were determined from the same plates after modification, taking $\mathrm{ns}=1.46, \mathrm{ks}=0$ for the organic layer.

Electrochemistry. Electrochemical experiments were performed with an Ametek, Princeton Applied Research, VersaSTAT4 potentiostat/galvanostat and a Versa studio electrochemitery 2.44.4 version software. All experiments were carried out in ACN solutions deoxygenated with argon. All potentials are referred to the SCE electrode.

Condensation Imaging. The plate was cooled on a Peltier cell with a temperature regulation. A decrease of the temperature of $\sim 10{ }^{\circ} \mathrm{C}$ by reference to the room temperature permits to condensate the surrounding humidity on the sample surface. This phenomenon can be exalted by blowing a slow air stream in the direction of the plate. The condensation depends on the local affinities of the surface with water, in this way the hydrophobia differences on the surface are highlighted. The observation and the imaging are performed by means of a Zeiss 2000-c binocular loupe.

SEM. The images were recorded with a MET-FEG Zeiss (Zeiss SUPRA 40).

\section{RESULTS and DISCUSSION}

Photoreduction of Iodonium Salt. I was chosen as the iodonium salt because, after electron transfer, the nitrophenyl radical, the behavior of which under electrografting conditions is well-known, should be formed. ${ }^{31}$

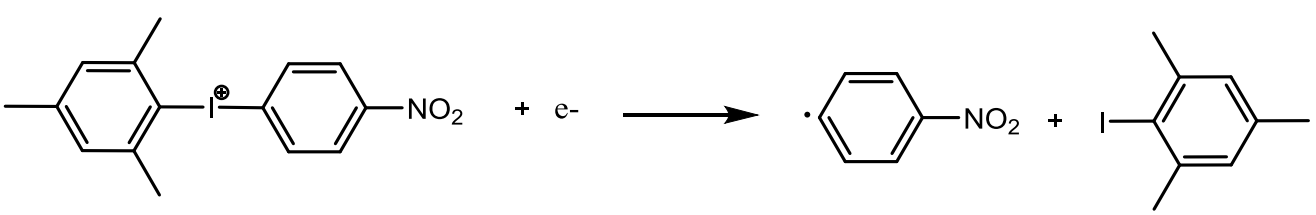

Moreover the advantage of this iodonium salt is that even if the 2,4,6-trimethylphenyl radical were formed in parallel to the nitrophenyl one, it could not react on surfaces due to steric hindrance. ${ }^{50}$ The cyclic voltammetry of $\mathbf{I}$ allowed comparing its reduction potential with those of the different photosensitizers (PS) (Figure 1). It shows a first irreversible wave located at $E \mathrm{p}_{\mathrm{c}}=-0.52 \mathrm{~V} / \mathrm{SCE}$ assigned to the reduction of the iodonium chemical function (equation 1), 
which disappears on the third scan. It is followed by the reversible wave of the nitrophenyl group $\left(\mathrm{Ep}_{\mathrm{c}}=-1.07 \mathrm{~V} / \mathrm{SCE}\right.$, by comparison with $\mathrm{Ep}_{\mathrm{c}}=-1.03 \mathrm{~V} / \mathrm{SCE}$ for nitrobenzene under the same conditions). The voltammogram of $\mathbf{I}$ indicates that this iodonium salt is more difficult to reduce than the 4-nitrobenzenediazonium tetrafluoroborate salt: $\mathrm{Ep}_{\mathrm{c}}=+0.20 \mathrm{~V} / \mathrm{SCE}$ under identical conditions. ${ }^{26}$ In both cases (I and 4-nitrobenzenediazonium) the same nitrophenyl radical is formed.

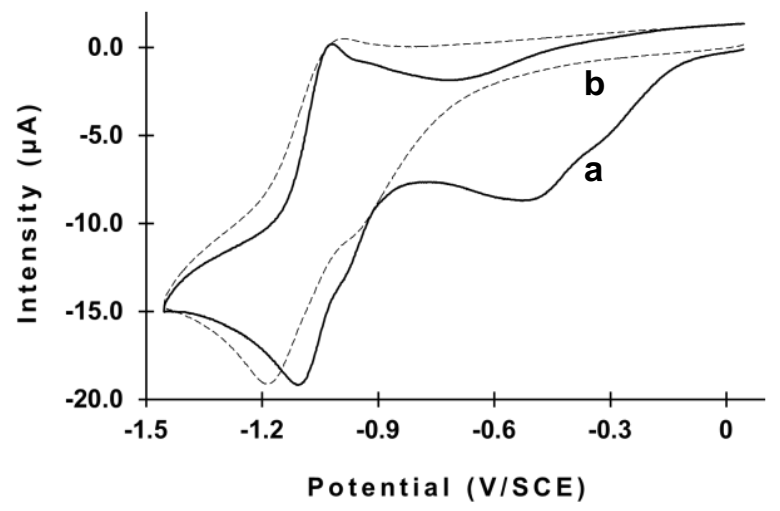

Figure 1. Cyclic voltammetry of $\mathbf{I}$ in $\mathrm{ACN}+0.1 \mathrm{M} \mathrm{NBu} \mathrm{BF}_{4}$ on a $\mathrm{GC}$ electrode a) first, b) third cycle. $\mathrm{V}=0.1 \mathrm{Vs}^{-1}$. The first cathodic wave disappears because of the electrografting of $\mathbf{I}$ onto Au.

Table 1. Redox Potentials of Photosensitizers and Iodonium salt (I). ${ }^{a}$

\begin{tabular}{cccc}
\hline & \multicolumn{3}{c}{$\mathrm{E}_{1 / 2}(\mathrm{~V})(\Delta \mathrm{Ep} / \mathrm{mV}) v s . \mathrm{SCE}$} \\
\cline { 2 - 4 } Compound & $\mathrm{PS}^{+} / \mathrm{PS}$ & $\mathrm{PS}^{+} / \mathrm{PS}^{*}$ & $1^{\text {st }}$ reduction process \\
\hline$\left[\mathrm{Ru}(\mathrm{bpy})_{3}\right]^{2+}$ & $1.28(60)$ & -0.75 & $-1.30(60)$ \\
{$\left[\mathrm{Cu}(\mathrm{dpp})_{2}\right]^{+}$} & $0.69(50)$ & -1.03 & $-1.67(60)$ \\
{$\left[\mathrm{Cu}(\mathrm{dap})_{2}\right]^{+}$} & $0.61(60)$ & -1.19 & $-1.75(50)$ \\
$\mathbf{I}$ & & & $-0.52^{\mathrm{b}}$
\end{tabular}

${ }^{\mathrm{a}}$ in deoxygenated ACN $+0.1 \mathrm{M} \mathrm{TBAP}\left(v=0.1 \mathrm{Vs}^{-1}\right) ;{ }^{\mathrm{b}}$ irreversible process, the potential corresponds to $\mathrm{Ep}_{\mathrm{C}}$.

The redox potentials of the three photosensitizers (Table 1) are in accordance with previously published values for both copper based $\mathrm{PS}^{51}$ and $\left[\mathrm{Ru}(\mathrm{bpy})_{3}\right]^{2+} .{ }^{52}$ In the cathodic part, the first systems correspond to the one-electron reduction centered on the ligand, whereas in the anodic one, the systems correspond to the oxidation of the metal. All of them are reversible. The redox potentials in Table 1 indicate that the direct thermal reduction of $\mathbf{I}$ by PS is prohibited since the reaction would be, in the more favorable case, endergonic by more than 1 
$\mathrm{eV}$. To evaluate the photoinduced electron transfer ability, the photophysical properties of the three complexes were recorded in ACN under argon (Table 2).

Table 2. Photophysical Properties of the three Photosensitizers. ${ }^{\text {a }}$

\begin{tabular}{|c|c|c|c|c|c|c|c|}
\hline Photosensitizer & $\begin{array}{c}\lambda_{\text {abs. }}{ }^{\mathrm{b}} / \mathbf{n m} \\
\left(\varepsilon / \mathbf{M}^{-1} \mathbf{c m}^{-1}\right)\end{array}$ & $\begin{array}{c}\lambda_{\text {em. }}{ }^{c} / \\
\text { nm }\end{array}$ & $\phi_{L}{ }^{d}$ & $\tau_{\mathbf{L}}{ }^{\mathrm{e}} /$ & $\begin{array}{l}\mathbf{k}_{\mathrm{q}}{ }^{\mathrm{f}} / \\
\mathbf{M}^{-1} \mathbf{s}^{-1}\end{array}$ & $\begin{array}{l}\Delta \mathbf{G}^{\circ \mathrm{g}} \\
/ \mathbf{e V}\end{array}$ & $\phi_{\mathbf{R}}{ }^{\mathrm{h}}$ \\
\hline$\left[\mathrm{Ru}(\mathrm{bpy})_{3}\right]^{2+}$ & $450(13500)$ & 610 & 0.062 & 850 & $6 \times 10^{8}$ & -0.23 & 0.06 \\
\hline$\left[\mathrm{Cu}(\mathrm{dpp})_{2}\right]^{+}$ & $\begin{array}{c}440(3200) \\
550(1500) \mathrm{sh}\end{array}$ & 720 & $<10^{-4}$ & 115 & $2 \times 10^{9}$ & -0.51 & 0.24 \\
\hline$\left[\mathrm{Cu}(\mathrm{dap})_{2}\right]^{+}$ & $\begin{array}{c}430(2400) \\
480(1900) \mathrm{sh}\end{array}$ & 690 & $<10^{-4}$ & 116 & $4 \times 10^{9}$ & -0.67 & 0.29 \\
\hline
\end{tabular}

a in ACN under argon; ${ }^{\mathrm{b}}$ absorption maximum; ${ }^{\mathrm{c}}$ emission maximum; ${ }^{\mathrm{d}}$ luminescence quantum yield; ${ }^{\mathrm{e}}$ lifetime $;{ }^{\mathrm{f}}$ quenching rate constant, ${ }^{\mathrm{g}} \Delta \mathrm{G}^{\circ}$ and ${ }^{\mathrm{h}}$ quantum yield for the photoinduced electron transfer process between PS and $\mathbf{I}$.

After excitation in their maximum absorption band, the PS exhibit an emission attributed to a triplet metal to ligand charge transfer state $\left({ }^{3} \mathrm{MLCT}\right)$, they exhibit an emission, ${ }^{53}$ with a lifetime long enough to take part to a bimolecular quenching process. The excited state oxidation potentials of the complexes can be estimated from the ground state potentials (Table 1) and emission energies (equation 2$)^{54}$ :

$$
\mathrm{E}_{1 / 2}\left(\mathrm{PS}^{+} / \mathrm{PS}^{*}\right)=\mathrm{E}_{1 / 2}\left(\mathrm{PS}^{+} / \mathrm{PS}\right)-\mathrm{E}_{00}
$$

where $\mathrm{E}_{00}$ is approximated to the emission energy at room temperature of the photosensitizers. The excited states, $\mathrm{Cu}$-based PS $*$ and $\left[\mathrm{Ru}(\mathrm{bpy})_{3}\right]^{2+*}$, can reduce $\mathbf{I}$ (Table 1$)$. The $\Delta \mathrm{G}^{\circ}$ of the redox quenching reaction (equation 3 ) is estimated to $-0.51,-0.67$ and $-0.23 \mathrm{eV}$ respectively

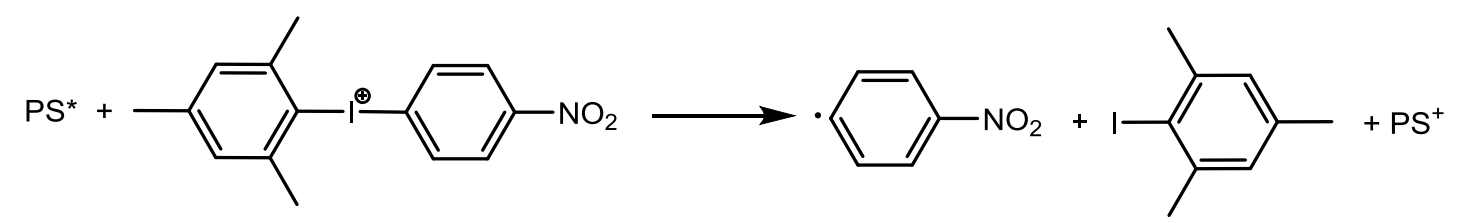

(Table 2).

The photoreduction process was followed by the evolution of the electronic absorption spectra of a mixture of a given PS with large excess of $\mathbf{I}$ upon continuous irradiation carried out between 400-800 $\mathrm{nm}$. As an example Figure 2 shows the evolution of a solution of $\left[\mathrm{Cu}(\mathrm{dpp})_{2}\right]^{+}$with $\mathbf{I}$.

During irradiation the typical absorption bands of $\left[\mathrm{Cu}(\mathrm{dpp})_{2}\right]^{+}$at 440 and $550 \mathrm{~nm}$ disappear with the emergence of two new ones at 559 and $760 \mathrm{~nm}$ due to $\left[\mathrm{Cu}(\mathrm{dpp})_{2}\right]^{2+}$ altogether with the appearance of an isosbestic point at $615 \mathrm{~nm} .{ }^{55}$ This evolution demonstrates the 
photoinduced electron transfer process between $\left[\mathrm{Cu}(\mathrm{dpp})_{2}\right]^{+}$and $\mathbf{I}$ leading to $\left[\mathrm{Cu}(\mathrm{dpp})_{2}\right]^{2+}$ and the concomitant reduction of $\mathbf{I}$. A blank experiment using a mixture of both species in dark does not show any evolution with time. Continuous irradiation of a mixture of $\left[\mathrm{Cu}(\mathrm{dap})_{2}\right]^{+}$ and I follows a similar evolution with the disappearance of bands at 430 and $480 \mathrm{~nm}$ and the appearance of an absorbance at $660 \mathrm{~nm}$ and an isosbestic point at $617 \mathrm{~nm}$ (Figure S2 in Supporting Information). In the case of a solution of $\left[\mathrm{Ru}(\mathrm{bpy})_{3}\right]^{2+}$ and $\mathbf{I}$ under irradiation, the typical initial absorption band of $\left[\mathrm{Ru}(\mathrm{bpy})_{3}\right]^{2+}$ is replaced by those of $\left[\mathrm{Ru}(\mathrm{bpy})_{3}\right]^{3+}$ at 420 and $680 \mathrm{~nm}^{56}$ (Figure S3 in Supporting Information). However in the latter case the reaction is much slower in accordance with the markedly less reductive power of $\left[\mathrm{Ru}(\mathrm{bpy})_{3}\right]^{2+*}$ compared to those of $\left[\mathrm{Cu}(\mathrm{dpp})_{2}\right]^{+*}$ or $\left[\mathrm{Cu}(\mathrm{dap})_{2}\right]^{+*}$.

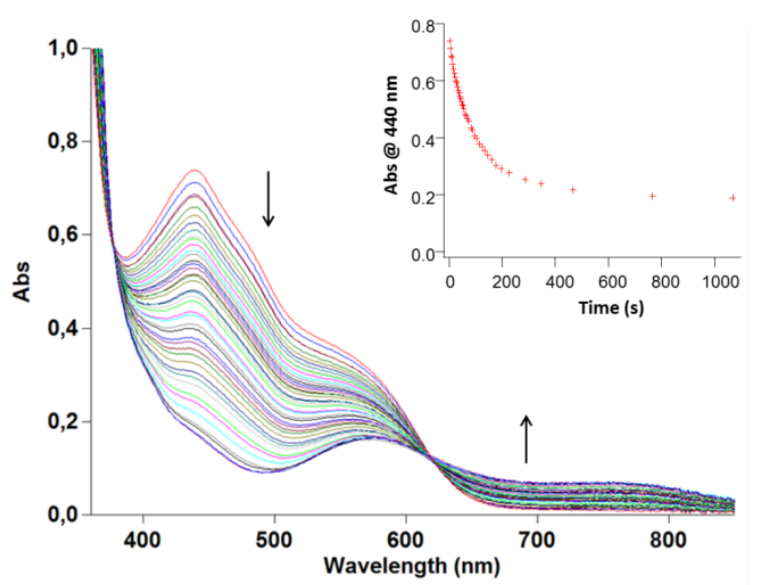

Figure 2. Absorption spectra of a mixture of $\left[\mathrm{Cu}(\mathrm{dpp})_{2}\right]^{+}(0.2 \mathrm{mM})$ and $\mathbf{I}(2 \mathrm{mM})$ in deoxygenated $\mathrm{ACN}$ during continuous irradiation. Inset: evolution of the absorbance at $440 \mathrm{~nm} v s$ irradiation time. The bands relative to $\left[\mathrm{Cu}(\mathrm{dpp})_{2}\right]^{+}$decrease while those of $\left[\mathrm{Cu}(\mathrm{dpp})_{2}\right]^{2+}$ increase concomitantly.

The quenching constants $\left(\mathrm{k}_{\mathrm{q}}\right)$ of the different PS* by $\mathbf{I}$ were determined by a Stern-Volmer plot according to equation 4 , where $\tau$ and $\tau^{\circ}$ are respectively the luminescence lifetime of the complex with and without $\mathbf{I}$.

$$
\frac{\tau^{\circ}}{\tau}=1+\tau^{\circ} \mathrm{k}_{\mathrm{q}}[\mathbf{I}]
$$

$\mathrm{k}_{\mathrm{q}}$ values are collected in Table 2, together with the $\Delta \mathrm{G}^{\circ}$ of the photoinduced electron transfer and the quantum yields $\left(\phi_{\mathrm{R}}\right)$ of the reaction. The values for $\Delta \mathrm{G}^{\circ}$ and $\mathrm{k}_{\mathrm{q}}$ show that the kinetics follows the thermodynamics of the reaction. The faster reaction is observed with $\left[\mathrm{Cu}(\mathrm{dap})_{2}\right]^{+}$ as the sensitizer. In that case, the quenching rate is in the same order of magnitude as the diffusion rate limit. The quantum yield of the reaction $\left(\phi_{R}\right)$ was also calculated with the three 
PS (Table 2). It is much higher when the Cu-based photosensitizers are used instead of $\left[\mathrm{Ru}(\mathrm{bpy})_{3}\right]^{2+}$.

Photografting of I. Photografting of I was performed under similar conditions for each photosensitizer in the presence of DIPEA (see experimental section for details). DIPEA is used as sacrificial agent ${ }^{57}$ to regenerate PS after the photoinduced electron transfer reaction with I (see next section). Irradiation was maintained until evaporation of ACN ( 10 min). After rinsing with ethanol in an ultrasonic cleaner and drying, the Au plate was examined by IR, XPS, cyclic voltammetry and water contact angles.

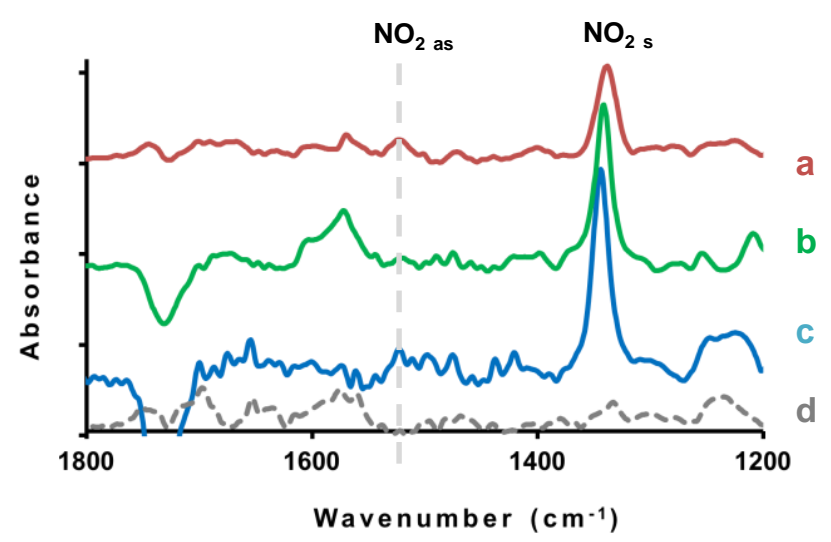

Figure 3. IRRAS spectrum of $A u$-I obtained with a) $\left[\mathrm{Cu}(\mathrm{dpp})_{2}\right]^{+}$, b) $\left[\mathrm{Cu}(\mathrm{dap})_{2}\right]^{+}$and c) $\left[\mathrm{Ru}(\mathrm{bpy})_{3}\right]^{2+}$. d) is a control sample without photosensitizer. The grafting of Au by $\mathbf{I}$ is attested by the signature of the $\mathrm{NO}_{2}$ group.

The IRRAS spectrum of the modified gold surface $A u$-I presents a main band located at 1354 $\mathrm{cm}^{-1}$ assigned to the symmetric stretching of the $\mathrm{NO}_{2}$ group (by comparison: 1522 and 1347 $\mathrm{cm}^{-1}$ of similar absorbance for neat nitrobenzene, Figure 3). The absorbance of the asymmetric stretching band $\left(1535 \mathrm{~cm}^{-1}\right)$ is much lower than that of the symmetric one, which corresponds to a nitrophenyl group standing up on the surface of gold, in agreement with the surface selection rules. The negative peaks at $1734 \mathrm{~cm}^{-1}$ correspond to some contamination during the recording of the blank sample.

The XPS survey spectrum of $A u$-I obtained with $\mathrm{Cu}(\mathrm{dpp})_{2}\left(\mathrm{BF}_{4}\right)$ in the presence of DIPEA presents the contributions of Au4f (28.4\%), C1s (48.5\%), O1s (19.8\%), N1s (2.9\%) and I3d $(0.5 \%)$ (Figure S4, Supporting Information). The N1s peak can be deconvoluted with two contributions at $400.0(2.3 \%)$ and $406.0 \mathrm{eV}(0.6 \%)$ (Figure 4); the former likely corresponds to amines (by partial reduction of the nitro group) and some contamination and the latter one to the surface nitrophenyl groups. Observation of Au4f indicates that the organic film presents pinholes as it does not shield completely the gold surface. The observation of I3d likely stems either from the grafting of some iodine radical or from adsorption of iodine. The high 
resolution XPS spectra for N1s and the atomic \% of the main XPS peaks obtained with the other two photosensitizers and for a blank experiment are reported in Figure S5 and Table S1 (Supporting Information), respectively. In the absence of photosensitizer there is no signal at $406 \mathrm{eV}$ corresponding to the nitrophenyl group.

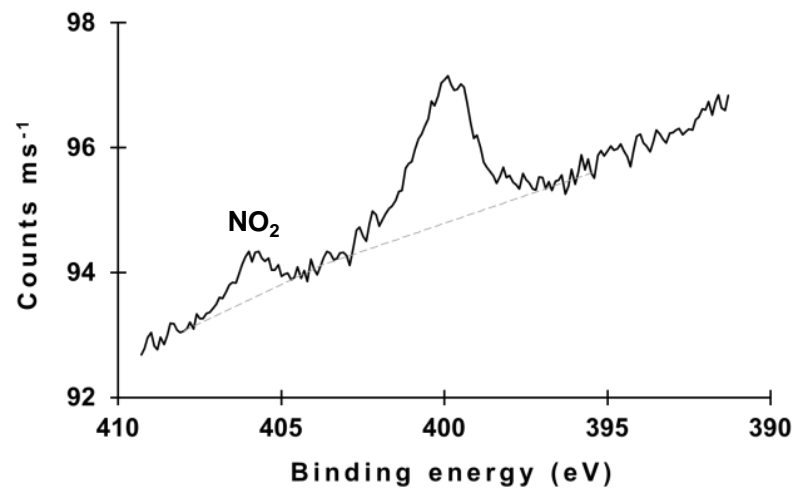

Figure 4. High resolution XPS spectrum of $A u$-I (N1s region). The grafting of Au by $\mathbf{I}$ is attested by the signature of the $\mathrm{NO}_{2}$ group.

The cyclic voltammetry in ACN of a small Au shard cut from a modified plate presents an irreversible peak at Ep $=-1.09 \mathrm{~V} / \mathrm{SCE}$ (under the same conditions, nitrobenzene is reduced reversibly at $\mathrm{Ep}=-1.03 \mathrm{~V} / \mathrm{SCE}$ ) and a prewave of unknown origin at less negative potentials (Figure 5A). The irreversibility observed on the modified shard is due to the very small number of nitrophenyl groups on the surface that are reduced to radical anions and then protonated by residual water. In an aqueous acidic medium, the grafted nitrophenyl groups are reduced irreversibly at $\mathrm{Ep}=-0.36 \mathrm{~V} / \mathrm{SCE}$ (Figure 5B, under the same conditions nitrobenzene is reduced irreversibly by 4 to 6 electrons at $\mathrm{Ep}=-0.44 \mathrm{~V} / \mathrm{SCE})$. 
A

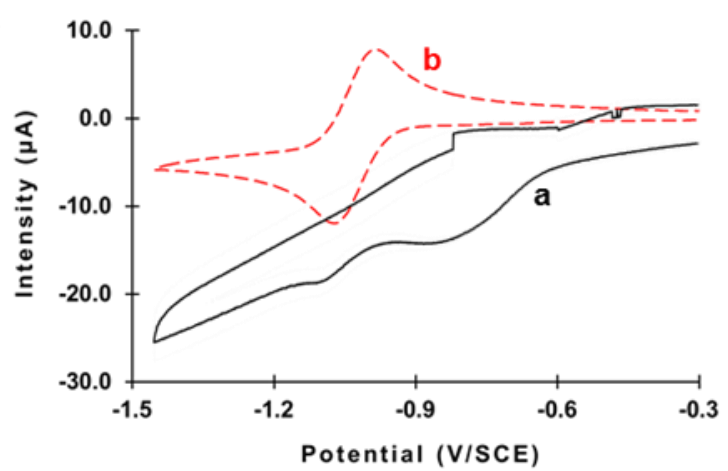

B

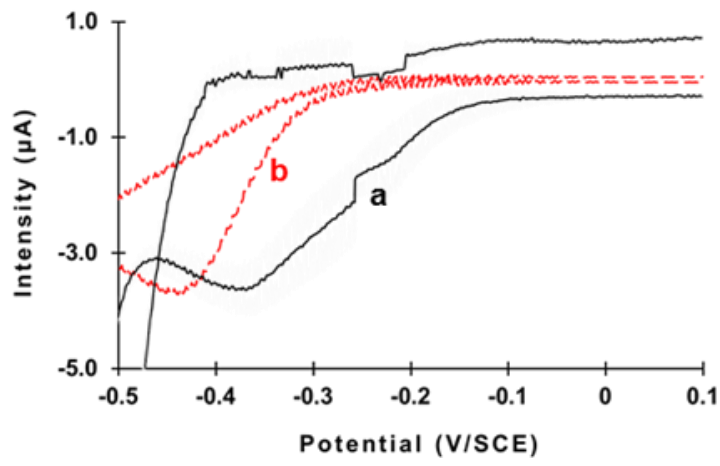

Figure 5. Cyclic voltammetry of a small shard cut in a modified $A u$-I plate. A) in $A C N+0.1 \mathrm{M} \mathrm{NBu}_{4} \mathrm{BF}_{4} \cdot$ a) $A u-1$, b) nitrobenzene. B) in $\mathrm{EtOH} / \mathrm{H}_{2} \mathrm{O}(90 / 10 \mathrm{~V} / \mathrm{V})+0.1 \mathrm{M} \mathrm{HCl} \mathrm{a)} A u$-I, b) nitrobenzene. The plates were modified through the grafting of $\mathbf{I}$ in the presence of $\mathrm{Aa}) \mathrm{Cu}(\mathrm{dpp})_{2}\left(\mathrm{BF} \mathrm{F}_{4}\right)$ and $\left.\mathrm{Ba}\right)\left[\mathrm{Ru}(\mathrm{bpy})_{3}\right]\left(\mathrm{PF}_{6}\right)_{2}$. The grafted nitrophenyl groups are evidenced by the signature of the $\mathrm{NO}_{2}$ group reduction.

AFM gives insight into the topography and the thickness of the grafted surfaces. In the case of $A u$-I obtained with $\left[\mathrm{Cu}(\mathrm{dpp})_{2}\right]^{+}$in the presence of DIPEA (Figures 6 Aa-d), AFM shows that the surface is quite inhomogeneous with high clumps of organic matter, as always observed after grafting radicals. ${ }^{58}$ Figure $6 \mathrm{Ab}$ (phase image) presents lighter yellow zones that correspond to pinholes, which explains the presence of the Au signal in the XPS spectra. The dry state film thickness was estimated to $54.6 \mathrm{~nm}$ (mean value measured on a $10 \times 10 \mu \mathrm{m}^{2}$ surface) that can be compared to the value of $9.2 \mathrm{~nm}$ obtained without DIPEA; in the latter case high aggregates separated by ungrafted zones are observed (Figure 6B).

These results are confirmed by ellipsometry. In the presence of DIPEA, the thicknesses of the three $A u$-I films obtained from the three PS are in the $45-49 \pm 10 \mathrm{~nm}$ range. 


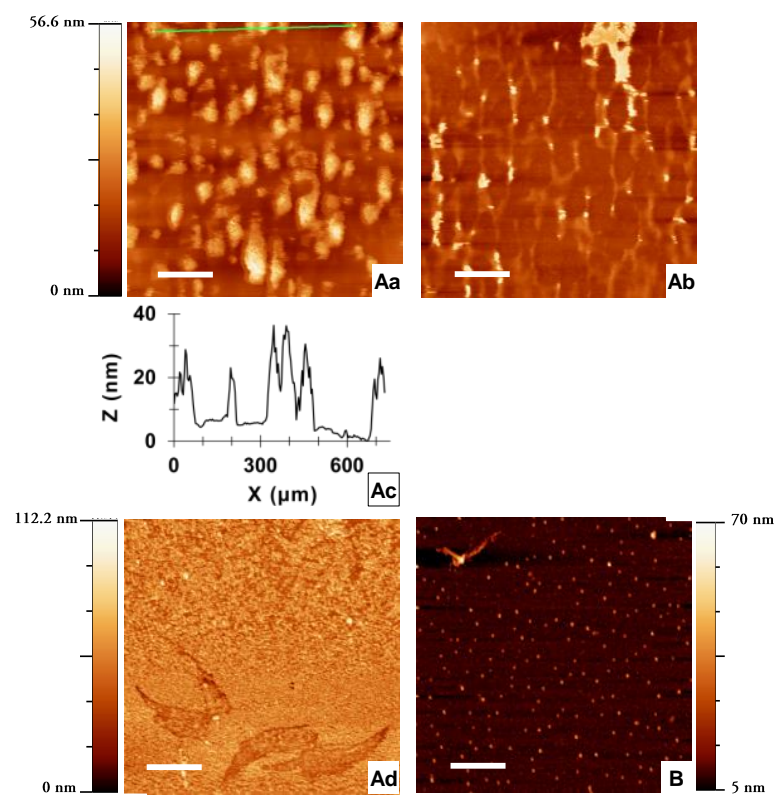

Figure 6. AFM image of an $A u$-I film obtained with $\left[\mathrm{Cu}(\mathrm{dpp})_{2}\right]^{+}$. A) In the presence and B) in the absence of DIPEA. Aa, Ad, B) Topographic images and Ab) phase image; Ac) topographic profile along the upper limit of Aa. Images Ad and B indicate a mean thickness of 54.6nm in the presence of DIPEA (Ad), but only $9.2 \mathrm{~nm}$ without it (B). The phase image Ab shows the presence of pinholes in the film. Scale bars: $200 \mathrm{~nm}$ for Aa and $\mathrm{Ab}, 2 \mu \mathrm{m}$ for Ad and B.

These different characterizations indicate that $\mathbf{I}$ can be used to graft aryl radicals on gold using a photoinduced electron transfer process, which leads to aromatic organic films with 45-49 nm thickness.

Patterning of an Au surface by I. A gold grid $\left(\sim 1 \mathrm{x} 1 \mathrm{~cm}^{2}\right)$ was used as a mask and placed on the surface of an Au plate; a solution of $\mathbf{I}$ and $\left[\mathrm{Cu}(\mathrm{dpp})_{2}\right]^{+}$was deposited on the surface and irradiation of the setup was performed as described above. Figures $7 \mathrm{a}$ and $\mathrm{b}$ compare an image of the grid used as a mask and an image of the patterned surface obtained by condensation (same scale); it evidences a transfer of the image of the grid on the gold surface. Figures $7 \mathrm{c}, \mathrm{d}$ and e compare images of the patterned surface obtained by condensation and SEM. By condensation the masked parts of the Au surface are covered with water droplets as they are more hydrophilic than the nitrophenyl modified spots. SEM also permits to observe the image of the grid. These images confirm the patterning of the surface under irradiation using a mask. The three PS gave similar results. The thickness (measured by AFM) of the grafted spots is similar to that obtained on a uniformly grafted surface. 

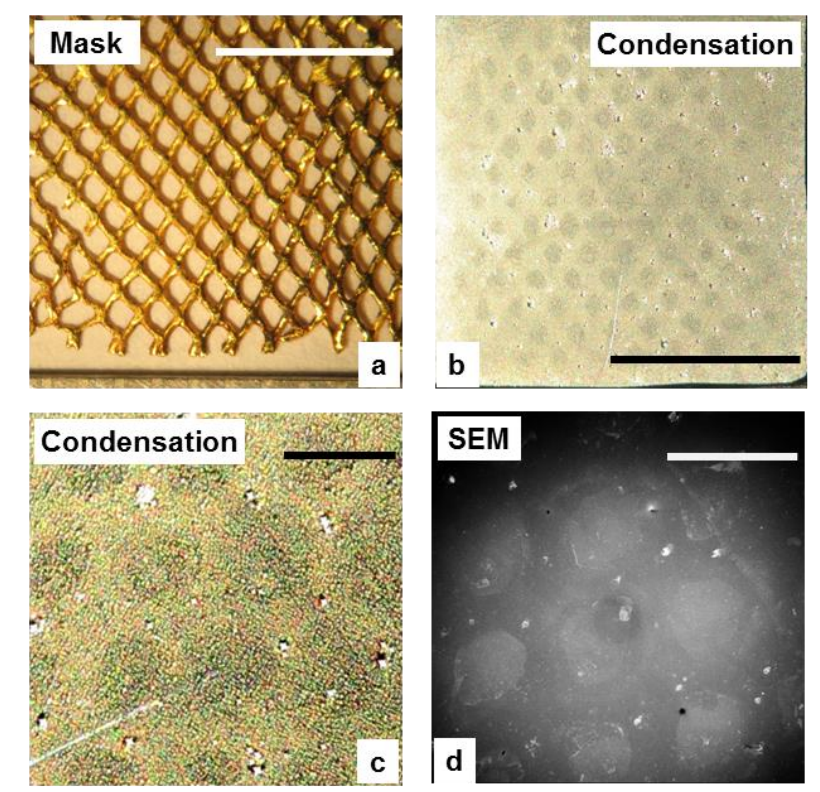

Figure 7. Patterning on an Au surface by photografting of $\mathbf{I}$. a) Optical image of the gold grid used as a mask. b) Condensation image of a patterned Au surface. c) Condensation and d) SEM images of the patterned $A u$-I surface. Scale bars: $5 \mathrm{~mm}$ for a) and b) and $500 \mathrm{~nm}$ for c) and d).

These results allow us to propose a mechanism, which is basically similar to that observed with diazonium salts ${ }^{26}$ and also to the electrografting mechanism of iodonium salts (Scheme 2).8

Upon irradiation with visible light, the excited state of PS, PS*, is formed (R1, Scheme 2). It reduces the iodonium salt $\mathbf{I}$ to give the nitrophenyl radical $(\mathbf{R 2}),{ }^{26}$ the aryl iodide ArI and $\mathrm{PS}^{+}$. The nitrophenyl radical can undergo three reactions with: i) the gold surface (R3), ii) a first grafted nitrophenyl group (R4) and, iii) PS* to give the nitrophenyl anion (R7) that is likely protonated by residual water. Reactions $(\mathbf{R 4}+\mathbf{R 5}+\mathbf{R 6})$ lead to the formation of a polynitrophenyl film bonded to the gold surface. Reaction (R4) produces a cyclohexadienyl radical II that gives an aromatic grafted dimer upon oxidation (R5). In the case of diazonium salts, this oxidation corresponds to the transfer of $-\left(\mathrm{e}^{-}+\mathrm{H}^{+}\right)$and can be achieved by the concomitant reduction of the diazonium salt. ${ }^{59-61}$ Since iodonium salts are poorer oxidants, they cannot be involved in reaction (R5). The possible oxidants in the solution are either PS ${ }^{+}$ (Table 1$)$ or the unstable DIPEA ${ }^{++}\left(\mathrm{Ep}_{\mathrm{a}}(\mathrm{Irr})[\mathrm{DIPEA}]=+0.81 \mathrm{~V} / \mathrm{SCE}\right.$ (in $\mathrm{ACN}+0.1 \mathrm{M}$ $\left.\mathrm{NBu}_{4} \mathrm{BF}_{4}, \mathrm{v}=0.1 \mathrm{Vs}^{-1}\right)$. DIPEA ${ }^{+}$is formed by reduction of $\mathrm{PS}^{+}$, allowing the regeneration of PS (R8) and the production of a stationary concentration of nitrophenyl radical sufficient to induce a modification of the gold surface. As shown by the different thicknesses observed in the presence or absence of DIPEA, (respectively 45-49 and $9.2 \mathrm{~nm}$, the photografting is more efficient in the presence of DIPEA. In the absence of DIPEA a large part of the photoproduced nitrophenyl radicals are reduced to their anionic form by $\mathrm{Cu}$-based PS* (R7), 
therefore preventing the effective grafting on the surface (as deduced from the comparison between the oxidation potential of Cu-based PS* (see Table 1) and the reduction potential of the nitrophenyl radical, $\left.\mathrm{Ep}_{\mathrm{c}}\left(\mathrm{NO}_{2}-\mathrm{Ph}^{\circ} / \mathrm{NO}_{2}-\mathrm{Ph}^{-}\right)=-0.80 \mathrm{~V} / \mathrm{SCE}^{62}\right)$. Blank irradiation of the different PS and DIPEA did not evidence a reaction between PS* and DIPEA.

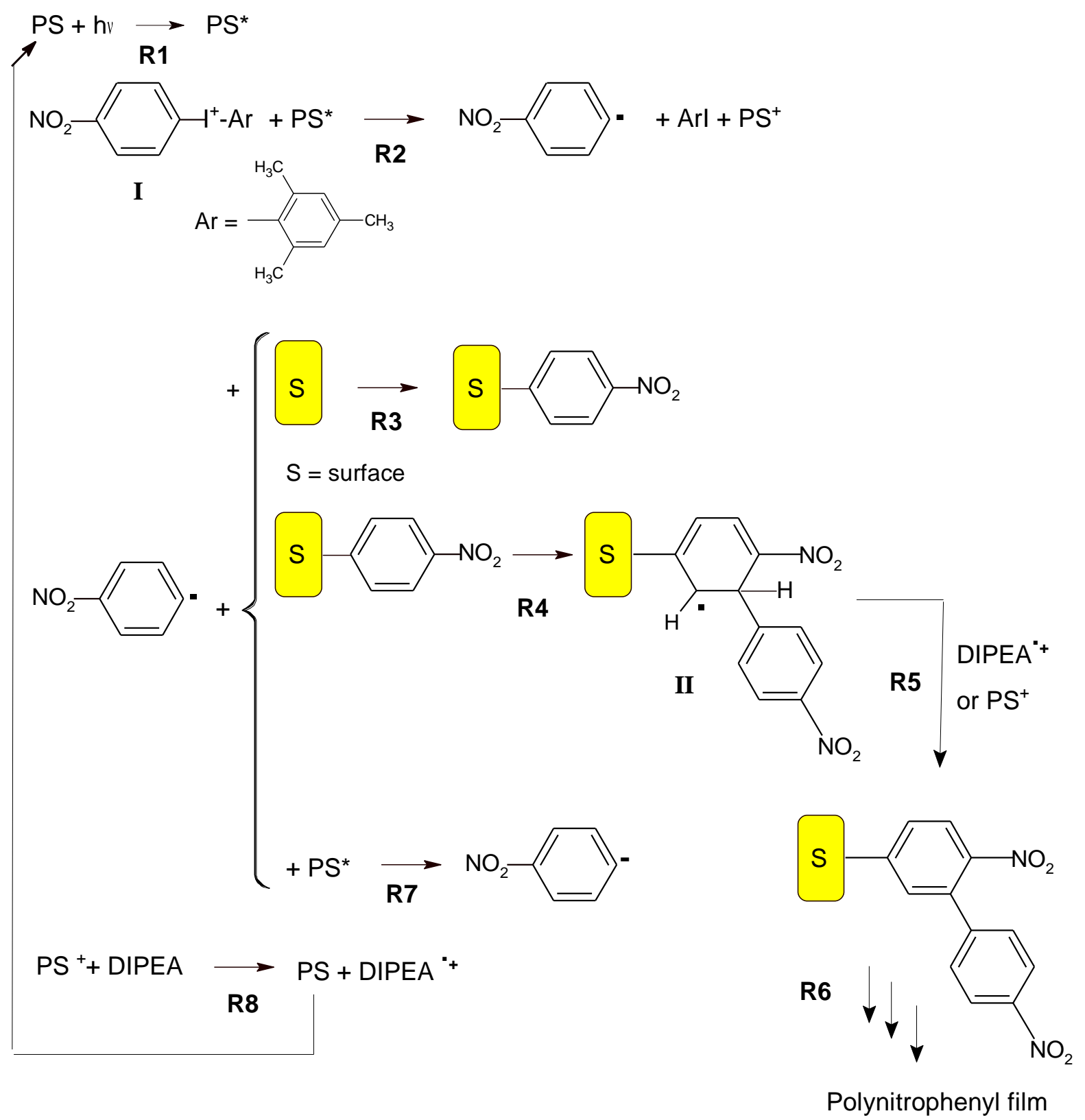

Scheme 2. Mechanism of the photografting of iodonium salts on gold. PS stands for any of the three photosensitizers. 


\section{CONCLUSIONS}

The photografting of iodonium salts permits to pattern surfaces with aryl groups. This should not be possible using diazonium salts that react spontaneously with most surfaces. ${ }^{32}$ Herein the photopatterning has been achieved with three photosensitizers and the 4-nitrophenyl2,4,6-trimethylphenyliodonium salt. In the presence of DIPEA as electron donor added in the solution a thicker film is obtained on a gold surface. The reaction can be extended to other substrates and used in different applications. For example a surface could be photografted with perfluoroaryl groups except in arrays of small lines; an aqueous flow should be contained in the lines between the hydrophobic surfaces to give surface-tension-confined microfluidic devices. It should also be possible to create patterns able to attach selectively proteins or other biomolecules. The advantage of photolithography over other patterning methods is that multiple patterns can be drawn from a single mask permitting to produce at the same time a large number of patterned surfaces as in the microelectronic industry.

Supporting Information available: experimental setup, photoinduced electron transfer under continuous irradiation, XPS for $A u$-I. This material is available free of charge via the Internet at http://pubs.acs.org.

\section{AUTHOR INFORMATION}

\section{Corresponding authors}

*E-mail : jean.pinson@univ-paris-diderot.fr

*E-mail : alain.deronzier4710@orange.fr

- ORCID Jean Pinson: 0000-0001-6176-8636

\section{Author Contributions}

The manuscript was written through contributions of all authors who have given approval to the final version.

\section{Notes}

The authors declare no competing financial interest. 


\section{ACKNOWLEDGMENTS}

This work was supported by Universities Paris Diderot and Grenoble Alpes and by CNRS. We are grateful to Dr P. Decorse and Dr J.-M. Noël for, respectively, the XPS spectra and the SEM images and also to the undergraduate students Bruno Sousa Macedo and John Diafera from Grenoble Alpes University who spent 1 month on the project.

\section{REFERENCES}

${ }^{1}$ Protected Metal Clusters from Fundamentals to Applications. Tsukuda, T.; Häkkinen, H. eds., Elsevier, Amsterdam, Netherlands. 2015.

${ }^{2}$ Fabre, B.; Pujari, S. P.; Scheres, L.; Zuilhof, H. Micropatterned ferrocenyl monolayers covalently bound to hydrogen-terminated silicon surfaces: effects of pattern size on the cyclic voltammetry and capacitance characteristics. Langmuir 2014, 30, 7235-7243.

${ }^{3}$ Pujari, S. P.; Scheres, L.; Marcelis, A. T. M.; Zuilhof, H. Covalent surface modification of oxide surfaces. Angew. Chem., Int. Ed. 2014, 53, 6322-6356.

${ }^{4}$ Guerrero, G.; Alauzun, J. G.; Granier, M.; Laurencin, D.; Mutin, P. H. Phosphonate coupling molecules for the control of surface/interface properties and the synthesis of nanomaterials. Dalton Trans. 2013, 42, 12569-12585.

${ }^{5}$ Allongue, P.; Delamar, M.; Desbat, B.; Fagebaume, O.; Hitmi, R.; Pinson, J.; Savéant, J.-M. Covalent modification of carbon surfaces by grafting of functionalized aryl radicals produced from electrochemical reduction of diazonium salts. J. Am. Chem. Soc. 1992, 114, 5883-5884.

${ }^{6}$ Bélanger, D.; Pinson, J. Electrografting: a powerful method for surface modification. Chem.Soc. Rev., 2011, 40, 3995-4048.

${ }^{7}$ Berisha, A.; Chehimi, M. M.; Pinson, J.; Podvorica, F. I. Electrode Surface Modification Using Diazonium Salts. In Electroanalytical Chemistry; Bard, A.J., Zoski, C.G., Eds.; CRC Press: Boca Raton, FL, 2016; pp 115-224.

${ }^{8}$ Vase, K. H.; Holm, A. H.; Pedersen, S. U.; Daasbjerg, K. Immobilization of Aryl and Alkynyl Groups onto Glassy Carbon Surfaces by Electrochemical Reduction of Iodonium Salts. Langmuir 2005, 21, 8085-8089.

9 Zhou, X.; Boey, F.; Huo, F; Huang, L. Zhang, H. Chemically Functionalized Surface Patterning. Small 2011, 7, 2273-2289.

${ }^{10}$ Nie, Z.; Kumacheva, E. Patterning surfaces with functional polymers. Nature Materials 2008, 7, 277-289. 
${ }^{11}$ Downard, A.; Gross, A. J.; Simons, B. M. Patterned Molecular Layers on Surfaces in Aryl Diazonium Salts in New Coupling Reagents in Polymer and Surface Science, Chehimi, M. M; ed. Wiley-VCH, Weiheim, 2012, pp. 53-68.

${ }^{12}$ Wendeln, C.; Ravoo, B. J. Surface Patterning by Microcontact Chemistry. Langmuir 2012, 28, 5527-5538.

${ }^{13}$ Singh, M.; Haverinen, H. M.; Dhagat, P.; Jabbour, G. E. Inkjet Printing-Process and Its Applications. Adv. Mater. 2010, 22, 673-685.

14 Yamada, K., Henares, T. G.; Suzuki, K.; Citterio, D. Paper-Based Inkjet-Printed Microfluidic Analytical Devices. Angew.Chem.Int. Ed. 2015, 54, 5294-5310.

15 Amemiya, S.; Bard, A. J.; Fan, F.-R. F.; Mirkin, M. V.; Unwin, P. R. Scanning Electrochemical Microscopy. Annual Review of Analytical Chemistry 2008, 1, 95-131.

${ }^{16}$ Wittstock, G.; Schuhmann, W. Formation and Imaging of Microscopic Enzymatically Active Spots on an Alkanethiolate-Covered Gold Electrode by Scanning Electrochemical Microscopy. Anal. Chem. 1997, 69, 5059-5066.

${ }^{17}$ Ginger, D. S.; Zhang, H.; Mirkin, C.A. The Evolution of Dip-Pen Nanolithography. Angew. Chem. Int. Ed. 2004, 43, 30-45.

${ }^{18}$ Son, J. Y.; Shin, Y.-H.; Ryu, S.; Kim, H.; Jang, H. M. Dip-Pen Lithography of Ferroelectric PbTiO3 Nanodots. J. Am. Chem. Soc. 2009, 131, 14676-14678.

${ }^{19}$ Greenwood, J.; Phan, T. H.; Fujita, Y.; Li, Z.; Ivasenko, O.; Vanderlinden, W.; Van Gorp, H.; Frederickx, W.; Lu, G.; Tahara, K.; Tobe, Y.; Uji-i, H.; Mertens, S. F. L.; De Feyter, S. Covalent Modification of Graphene and Graphite Using Diazonium Chemistry: Tunable Grafting and Nanomanipulation ACS Nano 2015, 9, 5520-5535.

${ }^{20}$ Brooksby, P. A.; Downard, A. J. Nanoscale Patterning of Flat Carbon Surfaces by Scanning Probe Lithography and Electrochemistry. Langmuir 2005, 21, 1672-1675.

${ }^{21}$ Zhou, M.; Yu, Y.; Blanchard, P.-Y.; Mirkin, M. V. Surface Patterning Using Diazonium Ink Filled Nanopipette. Anal. Chem. 2015, 87, 10956-10962.

${ }^{22}$ Azevedo, J.; Fillaud, L.; Bourdillon, C.; Noël, J.-M.; Kanoufi, F. ; Jousselme, B. ; Derycke, V.; Campidelli, S. ; Cornut, R. Localized Reduction of Graphene Oxide by Electrogenerated Naphthalene Radical Anions and Subsequent Diazonium Electrografting. J. Am. Chem. Soc. 2014, 136, 4833-4836.

${ }^{23}$ Downard, A. J.; Garrett, D. J.; Tan E.S.Q. Microscale Patterning of Organic Films on Carbon Surfaces Using Electrochemistry and Soft Lithography. Langmuir 2006, 22, 1073910746-10749. 
${ }^{24}$ Campbell, S. A. Fabrication Engineering at the Micro and Nano Scale. Oxford University Press, Oxford, 2013.

25 Totzeck, M.; Ulrich, W.; Goehnermeier, A.; Kaiser, W. Pushing deep ultraviolet lithography to its limits. Nature Photonics 2007, 1, 629-631.

${ }^{26}$ Bouriga, M.; Chehimi, M. M.; Combellas, C.; Decorse, P.; Kanoufi, F.; Deronzier, A.; Pinson, J. Sensitized Photografting of Diazonium Salts by Visible Light. Chem. Mater. 2013, 25, 90-97.

${ }^{27}$ Verberne-Sutton, S. D.; Quarels, R. D.; Zhai, X.; Garno, J. C.; Ragains, J. R. Application of Visible Light Photocatalysis with Particle Lithography To Generate Polynitrophenylene Nanostructures. J. Am. Chem. Soc. 2014, 136, 14438-14444.

${ }^{28}$ Schroll, P.; Fehl, C.; Dankesreiter, S.; König, B. Photocatalytic surface patterning of cellulose using diazonium salts and visible light. Org. Biomol. Chem. 2013, 11, 6510-6514.

${ }^{29}$ Van Gorp, H.; Walke, P.; Braganca, A. M.; Greenwood, J.; Ivasenko, O.; Hirsch, B. E.; De Feyter, S. Self-Assembled Polystyrene Beads for Templated Covalent Functionalization of Graphitic Substrates Using Diazonium Chemistry. ACS Appl Mater. Interfaces 2018, 10, 12005-12012.

${ }^{30}$ Dirk, S. M.; Pylypenko, S.; Howell, S. W. Fulghum, J. E.; Wheeler, D. R. PotentialDirected Assembly of Aryl Iodonium Salts onto Silicon $\{100\}$ Hydride Terminated and Platinum Surfaces. Langmuir 2005, 24, 10899-10901.

${ }^{31}$ Vase, K. H.; Holm, A. H.; Kion, N.; Pedersen, S. U.; Daasbjerg, K. Covalent Grafting of Glassy Carbon Electrodes with Diaryliodonium Salts: New Aspects. Langmuir 2007, 23, 3786-3793.

${ }^{32}$ Matrab, T.; Combellas, C.; Kanoufi, F. Scanning electrochemical microscopy for the direct patterning of a gold surface with organic moieties derived from iodonium salt. Electrochem.Comm. 2008, 10, 1230-1234.

${ }^{33}$ Weissmann, M.; Baranton, S.; Coutanceau, C. Modification of Carbon Substrates by Aryl and Alkynyl Iodonium Salt Reduction. Langmuir 2010, 26, 15002-15009.

${ }^{34}$ Fontanesi, C.; Bortolotti, C. A.; Vanossi, D.; Marcaccio, M. Dissociation Dynamics of Asymmetric Alkynyl(Aryl)Iodonium Radicals: An ab Initio DRC Approach to Predict the Surface Functionalization Selectivity . J. Phys. Chem. A 2011, 115, 11715-11722.

${ }^{35}$ Florini, N.; Michelazzi, M.; Parenti, F.; Mucci, A.; Sola, M.; Baratti , C.; De Renzi, V.; Daasbjerg, K.; Pedersen, S. U.; Fontanesi, C. Electrochemically assisted grafting of 
asymmetric alkynyl(aryl)iodonium salts on glassy carbon with focus on the alkyl/aryl grafting ratio. J. Electroanal. Chem. 2013, 710, 41-47.

${ }^{36}$ Chan, C. K.; Beechem, T. E.; Ohta, T.; Brumbach, M. T.; Wheeler, D. R.; Stevenson K. J. Electrochemically Driven Covalent Functionalization of Graphene from Fluorinated Aryl Iodonium Salts. J. Phys. Chem. C 2013, 117, 12038-12044.

${ }^{37}$ Stevenson, K. J.; Veneman, P. A.; Gearba, R. I.; Mueller, K. M.; Holliday, B. J.; Ohtab, T.; Chan, C. K. Controlled covalent modification of epitaxial single layer graphene on $6 \mathrm{H}-\mathrm{SiC}$ (0001) with aryliodonium salts using electrochemical methods. Faraday Discuss., 2014, 172, 273-291.

${ }^{38}$ Charlton, M. R.; Suhr, K. J.; Holliday, B. J.; Stevenson, K. J. Electrochemical Modification of Indium Tin Oxide Using Di(4-nitrophenyl) Iodonium Tetrafluoroborate. Langmuir 2015, $31,695-702$.

${ }^{39}$ He, M.; Swager, T. M. Covalent Functionalization of Carbon Nanomaterials with Iodonium Salts. Chem. Mater. 2016, 28, 8542-8549.

${ }^{40}$ Gearba, R. I.; Kim, M.; Mueller, K. M.; Veneman, P. A.; Lee, K.; Holliday, B. J.; Chan, C. K.; Chelikowsky, J. R.; Tutuc, E.; Stevenson K. J. Atomically Resolved Elucidation of the Electrochemical Covalent Molecular Grafting Mechanism of Single Layer Graphene. Adv. Mater. Interfaces 2016, 1600196.

${ }^{41}$ van Druenen,M.; Davitt, F.; Collins, T.; Glynn, C.; O’Dwyer, C.; Holmes, J. D.; Collins G. Covalent Functionalization of Few-Layer Black Phosphorus Using Iodonium Salts and Comparison to Diazonium Modified Black Phosphorus. Chemistry of Materials 2018, 30, $\mathrm{XxXX}-\mathrm{XXXX}$.

${ }^{42}$ Crivello, J.V.; Lam, J. H. W. Dye-Sensitized Photoinitiated Cationic Polymerization. J. Polymer Sci. 1978, 16, 2441-2451.

${ }^{43}$ Fouassier, J. P.; Burr, D.; Crivello, J. V. Time-resolved laser spectroscopy of the sensitized photolysis of iodonium salts. J. Photochem. Photobiol. A, Chem. 1989, 49, 317-324.

${ }^{44}$ Kabatc, J. The Influence of a Radical Structure on the Kinetics of Photopolymerization J. Polym. Sci. A 2017, 55, 1575-1589.

${ }^{45}$ Xiao, P.; Dumur, F.; Zhang, J.; Graff, B.; Gigmes, D.; Fouassier, J. P.; Lalevée J. Naphthalimide-phthalimide Derivative Based Photoinitiating Systems for Polymerization Reactions under Blue Lights. J. Polym. Sci. A 2015, 53, 665-674.

${ }^{46}$ Ghosh, I.; Marzo, L.; Das, A.; Shaikh, R.; König, B. Visible Light Mediated Photoredox Catalytic Arylation Reactions Acc. Chem. Res. 2016, 49, 1566-1577 and references cited. 
${ }^{47}$ Ruthkosky, M.; Castellano, F. N.; Meyer, G. J. Photodriven Electron and Energy Transfer from Copper Phenanthroline Excited States. Inorg. Chem. 1996, 35, 6406-6412.

${ }^{48}$ Crosby, G. A.; Demas, J. N. Measurement of photoluminescence quantum yields. Review

J. Phys. Chem. 1971, 75, 991-1024.

49 Bowman, W. D.; Demas, J. N. Ferrioxalate actinometry. A warning on its correct use

J. Phys. Chem. 1976, 80, 2434-2435.

${ }^{50}$ Combellas, C.; Jiang, D. E.; Kanoufi, F.; Pinson, J.; Podvorica, F. I. Steric effects in the reaction of aryl radicals on surfaces, Langmuir 2009, 25, 286-293.

${ }^{51}$ Federlin, P.; Kern, J.-M.; Rastegar, A.; Dietrich-Buchecker, C.; Marmot, P. A.; Sauvage, J.P. Electrochemical properties of copper(I) catenates and some of their open chain analogues; correlation with their photophysical properties. New. J. Chem. 1990, 14, 9-12.

${ }^{52}$ Chambron, J.-C.; Sauvage, J.-P.; Amouyal, E.; Koffi, P. Ru(bipy) ${ }_{2}(\text { dipyridophenazine })^{2+}$ a complex with a long range directed charge transfer excited state. Nouv. J. Chim. 1985, 9, 527-529.

53 Armaroli, N. Photoactive mono- and polynuclear $\mathrm{Cu}(\mathrm{I})$-phenanthrolines. A viable alternative to Ru(II)-polypyridines? Chem. Soc. Rev. 2001, 30, 113-124.

${ }^{54}$ Meyer, T. J. Photochemistry of metal coordination complexes: metal to ligand charge transfer excited states. Pure Appl Chem. 1986, 58, 1193-1206.

${ }^{55}$ Huang, J.; Buyukcakir, O.; Mara, M. W.; Coskun, A.; Dimitrijevic, N. M.; Barin, G.; Kokhan, O.; Stickrath, A. B.; Ruppert, R.; Tiede, D. M.; Stoddart, J. F.; Sauvage J.-P.; Chen, L. X. Highly Efficient Ultrafast Electron Injection from the Singlet MLCT Excited State of Copper(I) Diimine Complexes to TiO2 Nanoparticles. Angew. Chem. Int. Ed. 2012, $51,12711-127$.

${ }^{56}$ Hidalgo-Acosta, J. C.; Méndez, M. A.; Scanlon, M. D ; Vrubel, H.; Amstutz, V.; Adamiak, W.; Opallo, M.; Girault, H. H. Catalysis of water oxidation in acetonitrile by iridium oxide nanoparticles. Chem. Sci. 2015, 6, 1761-1769.

57 Baralle, A.; Fensterbank, L.; Goddard, J.-P.; Ollivier, C. Aryl Radical Formation by Copper(I) Photocatalyzed Reduction of Diaryliodonium Salts: NMR Evidence for a $\mathrm{Cu}^{\mathrm{II}} / \mathrm{Cu}^{\mathrm{I}}$ Mechanism. Chem. Eur. J. 2013, 19, 10809 - 10813.

${ }^{58}$ Adenier, A.; Cabet-Deliry, E.; Chaussé, A.; Griveau, S.; Mercier, F.; Pinson, J.; Vautrin-Ul, C. Grafting of Nitrophenyl Groups on Carbon and Metallic Surfaces without electrochemical Induction. Chem. Mater. 2005, 17, 491-501. 
${ }^{59}$ Doppelt, P.; Hallais, G.; Pinson, J.; Podvorica, F.; Verneyre, S. Surface Modification of Conducting Substrates. Existence of Azo Bonds in the Structure of Organic Layers Obtained from Diazonium Salts. Chem. Mater. 2007, 19, 4570-4575.

${ }^{60}$ Combellas, C.; Kanoufi, F.; Pinson, J.; Podvorica, F. Time-of-Flight Secondary Ion Mass Spectroscopy Characterization of the Covalent Bonding between a Carbon Surface and Aryl Groups. Langmuir 2005, 21, 280.

${ }^{61}$ Adenier, A.; Combellas, C.; Kanoufi, F.; Pinson, J.; Podvorica, F. I. Formation of Polyphenylene Films on Metal Electrodes by Electrochemical Reduction of Benzenediazonium Salts. Chem. Mater. 2006, 18, 2021.

${ }^{62}$ Koefoed, L.; Vase, K. H.; Stenlid, J. H.; Brinck, T.; Yoshimura, Y.; Lund, H.; Pedersen, S. U.; Daasbjerg K. On the Kinetic and Thermodynamic Properties of Aryl Radicals Using Electrochemical and Theoretical Approaches. ChemElectroChem 2017, 3212-3221.

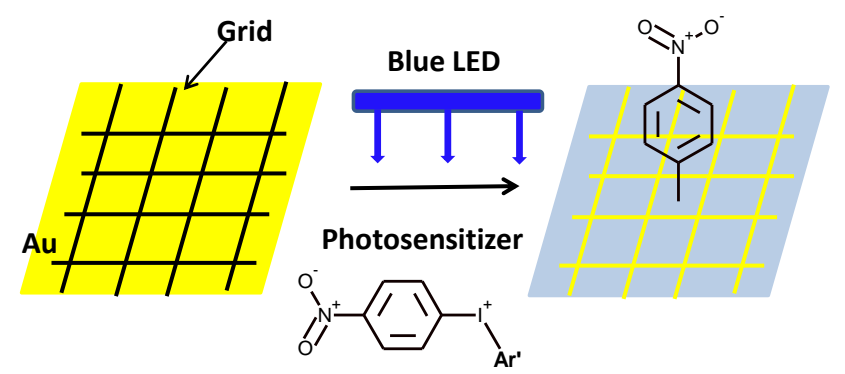

TOC 